\title{
A versatile biomass derived carbon material for supercapacitor, oxygen reduction reaction and oil/water separation
}

\author{
Shuyan Gao*, Xiaoge Li, Lingyu Li, Xianjun Wei \\ School of Chemistry and Chemical Engineering, Henan Normal University, Xinxiang \\ 453007,Henan, China; Email: shuyangao@htu.cn
}

\section{Keywords}

biowaste, heteroatom-doping, electrochemistry, oleophylic carbon aerogel, oil/water separation

\begin{abstract}
Directly pyrolyzing biowastes has attracted intensive interest, probably because this economical and facile method provides an efficient and versatile platform for synthesizing functional carbons. This study describes the synthesis of different functional carbons from poplar catkins via different processes for multi-purpose applications. Nitrogen and oxygen dual-doped carbon (NODC-800) derived from catkins delivers superior electrochemical characteristics as oxygen reduction reaction (ORR) catalyst in alkaline fuel cell to that of commercial $\mathrm{Pt} / \mathrm{C}$ in terms of catalytic activity, stability, resistance to methanol cross-over and $\mathrm{CO}$ poisoning. In addition, NODC-800 exhibits a high capacity $\left(\sim 251 \mathrm{~F} \mathrm{~g}^{-1}\right.$ at $\left.0.5 \mathrm{~A} \mathrm{~g}^{-1}\right)$ with nearly $100 \%$ retention rate after 1000 cycles as supercapacitors electrodes. An oleophylic carbon aerogel derived from catkins is proven to be superoleophilic and porous enough to "wet" with oils and organic liquids and repel water completely to achieve oil/water separation. This work is a successful case to take full advantage of raw materials from nature via multiple technologies to achieve energy sustainable development and protect environmental from oils and organic solvents spill.
\end{abstract}




\section{Introduction}

Energy crisis and environmental pollution are serious global issues hindering the stepping forward of society and industry, pushing an increasing demand to discover environmentally friendly and economical energy materials to achieve a sustainable future. Fuel cells (FCs) and supercapacitors (SCs) hold a great promise to be future green energy conversion and storage devices [1], which is conducive to solve the energy crisis and achieve sustainable development [2]. Disappointingly, the expensive, resource-constrained Pt-based electrocatalyst in commerce for oxygen reduction reaction (ORR) electrocatalyst hinders the widespread applications of FCs [3,4]; while state-of-the-art SCs tend to use chemically synthesized carbons, where costly and toxic chemicals are necessary for synthesis [5]; moreover, water pollution mainly caused by oil spillage and organic solvents leakage has become a widespread problem, and a number of conventional techniques have been used to separate oil and water, such as skimming, gravity separation, centrifugation, controlled burning and adsorption etc [6, 7]. Among them, the use of adsorbent materials has attracted extensive attention attributing to its simple process and excellent separating effect. Intensively and extensively, carbon materials have been the focus in either energy or environment fields as the catalysts, capacitor electrodes, supports or adsorbents. Biowastes have been used to synthesize various functional carbon materials widely applied in many fields, for example, ink, pigments and tattoos as early as 3000 years ago [8]. What attract growing attention in recent years are their applications in FCs [9], SCs [10], and adsorbents for oil/water separation [11], because of their good conductivity, large surface area and chemical stability $[1,12,13]$. Therefore, multi-functional carbon materials have been successfully synthesized from biowastes, e.g., N-doped porous carbon spheres prepared from fermented rice for ORR and SCs [8], N, S-doped porous carbon derived from sweet potato vines for ORR and SCs [14], hierarchically porous tubular carbon synthesized from wood for dye adsorbent and SCs [15], honeycomb-like porous carbon originated from pongam seed shells for enzymeless 
glucose sensor and SCs [16], N-doped carbon nanosheets prepared from silk for battery anodes and SCs [17], and so on. However, few researchers make full advantages of one single biowaste via different technologies to prepare different functional carbon materials applied in both energy-related and environment-related fields.

Cotton-like catkins from the blossoming poplar and willow trees contains carbon, nitrogen and oxygen elements and so on, hence, it is resonable to collect them as natural, cheap and sustainable precursors to prepare the self-doped functional carbon materials every spring. In this paper, we prepare nitrogen and oxygen dual-doped carbon (NODC-800) and oleophylic carbon aerogel (OCA) from poplar catkins via different technologies and attempt to apply them in FCs, SCs and oil/water separation, respectively. NODC-800, prepared via pyrolyzing the mixture of poplar catkins and $\mathrm{ZnCl}_{2}$ in tube furnace at $800{ }^{\circ} \mathrm{C}$, delivers interesting ORR electrochemical characteristics in alkalic medium. Its ORR peak potential is $-0.060 \mathrm{~V}$ versus $\mathrm{Hg} / \mathrm{HgO}$ in $\mathrm{O}_{2}$-saturated $0.1 \mathrm{~mol} \mathrm{l}^{-1} \mathrm{KOH}$ solution, which is $14 \mathrm{mV}$ more positive than that of $\mathrm{Pt} / \mathrm{C}$ catalyst under the same condition. Stability test exhibits its ORR catalytic activity with negligible attenuation after 1000 cycles, while Pt/C catalyst displays a 5.4\% decrease of current density. Compared with Pt/C catalyst, NODC-800 also eliminates the poor resistance to methanol cross-over and $\mathrm{CO}$ poisoning effect, delivering remarkable selectivity for ORR. As a result of the high surface area up to $1462.5 \mathrm{~m}^{2} \mathrm{~g}^{-1}$ and more accessible pore space, NODC-800 also shows a high capacity for SCs (251 F $\mathrm{g}^{-1}$ at $0.5 \mathrm{~A} \mathrm{~g}^{-1}$ ) with nearly $100 \%$ retention rate after 1000 cycles. OCA, yielded by directly pyrolyzing poplar catkins without activating agents, exhibits high absorption capacity of 81-171 times as much as its own weight and excellent recyclability for different oils and organic solvents. This work is a good example to take full advantage of raw materials from nature in various ways to achieve energy sustainable development, and protect environmental from oils and organic solvents spill.

\section{Experimental Section}




\subsection{Materials Synthesis:}

Poplar catkins, washed by ethanol and dried at $40{ }^{\circ} \mathrm{C}$, were mixed with $\mathrm{ZnCl}_{2}$ at a mass ratio of $1: 3$ and subsequently dried at $80{ }^{\circ} \mathrm{C}$, then, the obtained catkin- $\mathrm{ZnCl}_{2}$ mixtures were pyrolysized at $600{ }^{\circ} \mathrm{C}, 700{ }^{\circ} \mathrm{C}, 800{ }^{\circ} \mathrm{C}$ and $900{ }^{\circ} \mathrm{C}$ in $\mathrm{N}_{2}$ for 2 hours, respectively. After cooled to ambient temperature naturally, they were immersed in 2 $\mathrm{mol} \cdot \mathrm{l}^{-1} \mathrm{HCl}$ at $40{ }^{\circ} \mathrm{C}$ for 24 hours and repeatedly washed by ultrapure water until $\mathrm{pH}=7$ to remove any metal residue, and finally, dried in vacuum drying oven at $40{ }^{\circ} \mathrm{C}$ and labeled as NODC-600, NODC-700, NODC-800 and NODC-900, respectively.

Poplar catkins, washed by ethanol and dried at $40{ }^{\circ} \mathrm{C}$, were directly pyrolysized at $800{ }^{\circ} \mathrm{C}$ in $\mathrm{N}_{2}$ for 2 hours. After the reaction was cooled to ambient temperature naturally, the product was collected and labeled as OCA.

\subsection{Electrochemical Characterization:}

ORR experiments were tested on CHI6043E electrochemical workstation (Chenhua, Shanghai, China) at room temperature in a three-electrode cell with a piece of $\mathrm{Pt}$ foil (1 $\left.\mathrm{cm}^{2}\right), \mathrm{Hg} / \mathrm{HgO}$ electrode $(0.098 \mathrm{~V}$ relative to the reversible hydrogen electrode, $\mathrm{RHE})$ and glassy carbon electrode/rotation disk glassy carbon electrode (GCE/RD-GCE) coated with as-prepared carbon material as counter electrode, reference electrode and working electrode. The electrolyte was $\mathrm{N}_{2} / \mathrm{O}_{2}$-saturated $0.1 \mathrm{~mol} \cdot \mathrm{l}^{-1} \mathrm{KOH}$ solution. The result of rotation disk electrode (RDE) experiment was analyzed based on the following equations

$$
\frac{1}{J}=\frac{1}{\mathrm{~J}_{k}}+\frac{1}{B \omega^{0.5}}
$$

where $\mathrm{J}$ is the measured current density, $\mathrm{J}_{\mathrm{k}}$ is the kinetic-limiting current density, $\omega$ is the electrode rotating rate, $\mathrm{B}$ could be obtained from the slope of K-L plot.

$$
\mathrm{B}=0.2 \mathrm{nF} C_{0}\left(D_{0}\right)^{2 / 3} v^{-1 / 6}
$$


The constant 0.2 is adopted when the rotation rate is expressed in rpm, $\mathrm{n}$ is the number of electron transfer per $\mathrm{O}_{2}$ molecule, $\mathrm{F}$ is the Faraday constant $\left(\mathrm{F}=96,485 \mathrm{C} \mathrm{mol}^{-1}\right), \mathrm{C}_{0}$ and $\mathrm{D}_{0}$ are the bulk concentration $\left(1.2 \times 10^{-3} \mathrm{~mol}^{-1}\right)$ and diffusion coefficient $\left(1.9 \times 10^{-5}\right.$ $\mathrm{cm}^{2} \mathrm{~s}^{-1}$ ) of $\mathrm{O}_{2}$ in $0.1 \mathrm{~mol} \cdot \mathrm{l}^{-1} \mathrm{KOH}$ solution, and $v$ is the kinematic viscosity of 0.1 $\mathrm{mol} \cdot \mathrm{l}^{-1} \mathrm{KOH}$ solution.

To prepare working electrode, $1 \mathrm{mg}$ of the as-prepared carbon material was ultrasonically dispersed in $100 \mu \mathrm{l}$ ultrapure water with 5\% Nafion solution. Subsequently, $5 \mu \mathrm{l}$ and $10 \mu \mathrm{l}$ of the well-distributed catalyst ink were dropped onto the GCE and RD-GCE electrode surface, respectively, and then dried at room temperature for electrochemical measurements. For comparison, the commercial $\mathrm{Pt} / \mathrm{C}$ electrodes were prepared in the same way.

The SCs properties were evaluated in three or two electrodes system via CHI660E (Chenhua, Shanghai, China) electrochemistry workstation. For preparing the working electrodes, the mixture containing NODC-800, acetylene black and poly (tetrafluoroethylene) binder (weight ratio was 75:20:5) was pasted on the stainless steel grid (covered about $1 \mathrm{~cm}^{2}$ ), and they were dried at $85{ }^{\circ} \mathrm{C}$. In three-electrode system, aside from working electrode, the stainless steel grid and $\mathrm{Hg} / \mathrm{Hg}_{2} \mathrm{SO}_{4}$ electrode acted as counter electrode and reference electrode, respectively. In two-electrode system, both positive and negative were the above as-prepared working electrodes. All measurements were carried out in $1 \mathrm{~mol} \mathrm{l}^{-1} \mathrm{H}_{2} \mathrm{SO}_{4}$ solution. The specific capacitance, EIS and cycling stability were characterized in three-electrode system, while the power density and energy density were measured in two-electrode system. The specific capacitance was calculated based on the follow equations:

$$
\begin{aligned}
& \mathrm{C}_{1}=\mathrm{I}_{P} \times \mathrm{t} \quad(\text { Three-electrode system) } \\
& \mathrm{C}_{2}=2 \times \mathrm{I}_{P} \times \mathrm{t} \quad(\text { Two-electrode system) }
\end{aligned}
$$


where $\mathrm{C}\left(\mathrm{F} \mathrm{g} \mathrm{g}^{-1}\right)$ is the specific capacitance, $\mathrm{I}_{\mathrm{p}}\left(\mathrm{A} \mathrm{g}^{-1}\right)$ is current density, $\mathrm{t}(\mathrm{s})$ is discharge time.

The energy and power density were calculated based on the follow equations:

$$
\begin{aligned}
& \mathrm{E}=\frac{0.25 \mathrm{~V}^{2} C_{2}}{3.6} \\
& \mathrm{P}=\frac{3600 E}{t}
\end{aligned}
$$

where $\mathrm{E}\left(\mathrm{W} \mathrm{h} \mathrm{Kg}{ }^{-1}\right)$ and $\mathrm{P}\left(\mathrm{W} \mathrm{Kg}^{-1}\right)$ are energy and power density, respectively, V (V) is the real voltage excluding IR drop.

\subsection{Characterization:}

The morphologies and structures of the as-prepared samples were characterized by field-emission scanning electron microscopy (FESEM, Zeiss Supra 40), transmission electron microscopy (TEM, JEOL JEM-2100) and high resolution transmission electron microscope (HRTEM). The chemical compositions were confirmed using X-ray photoelectron spectroscopy (XPS, ESCALAB 250). The crystal structures and defects of samples were examined via X-ray diffraction (XRD, Bruker D 8, Cu-Ka, $\lambda=0.154 \mathrm{~nm}$ ) and Raman spectroscopy (Renishaw, $514 \mathrm{~nm}$ excitation laser). The porosity is measured at liquid nitrogen temperature $\left(-196.15{ }^{\circ} \mathrm{C}\right)$ using Micromeritics ASAP-2020. The chemical functional groups were analyzed by Fourier transform infrared spectroscopy (FTIR, FTS NEXUS, Thermo Nicolet Co., USA). The contact angles (CAs) were measured via contact angle meter (KRüSS DSA25).

\section{Results and Discussion}

Two different carbon materials (NODC-800 and OCA) were prepared from poplar catkins shown in Scheme 1. The preparation route (I): poplar catkins were mixed with $\mathrm{ZnCl}_{2}$ and carbonized in a tube furnace at $800{ }^{\circ} \mathrm{C}$ for 2 hours (details shown in Experimental Section). The product is labeled as NODC-800, which exhibits good performance for ORR and possesses a high capacitance for SCs. The preparation route 
(II): poplar catkins are directly carbonized in a tube furnace at $800{ }^{\circ} \mathrm{C}$ for 2 hours, and the product is marked as OCA, which delivers high absorption capacity and good recyclability for oils and organic solvents.

The morphology of the obtained NODC-800 was characterized by FESEM and TEM. NODC-800 has a highly rough surface with moss-like wrinkles, which is conducive to expose more contact surface area with the electrochemical actives and the used electrolyte (Figure 1A). The rough surface and porous structure of as-prepared sample are beneficial to increase the density of active sites in favor of ion transportation (Figure 1A and 1B). The d-spacing of NODC-800 observed by HRTEM is $0.35 \mathrm{~nm}$, corresponding to the (002) planes of graphite (Figure 1B illustration) [18]. To further explore the surface area and pore size of NODC-800, nitrogen adsorption-desorption isotherm was measured and shown in Figure 1C, exhibiting type IV isotherm. The non-zero adsorption at low relative pressure of $0.01[19,20]$ and the distinct hysteresis loop at relative pressure of 0.5-0.8 [21] indicate that both micropores and mesopores coexist in the sample $[14,22]$, in accordance with TEM results. The surface area and pore volume were calculated by Brunauer-Emmett-Teller (BET) equation and Barrett-Joyner-Halenda (BJH) model. Its surface area is $1462.5 \mathrm{~m}^{2} \mathrm{~g}^{-1}$, larger than most of graphite-base materials, whose are generally lower than $1000 \mathrm{~m}^{2} \mathrm{~g}^{-1}$ [23]. The total pore volume of NODC-800 is $1.31 \mathrm{~cm}^{3} \mathrm{~g}^{-1}$. Pore size distributions shown in Figure 1C clearly demonstrate its pore size is mainly around $3.6 \mathrm{~nm}$. The high specific surface area and porous structure of NODC-800 endow them with abundant edges and defects [24], which not only facilitate electron transfer [21], $\mathrm{O}_{2}$ diffusion [22], and offer reactant molecules high contact probability with the active sites [25-27], hereby contributing to ORR [21], but also are beneficial to reduce impedance and achieve higher specific capacitance [5].

The crystal structure of as-prepared sample was evaluated by XRD as shown in Figure 1D. Two broad and weak characteristic diffraction peaks centered at $2 \theta \approx 25^{\circ}$ and $43^{\circ}$ derive from the (002) diffraction of disordered carbon and the (101) diffraction 
of graphitized carbon [28], respectively, which is consistent with the HRTEM result. Similar results were gained from Raman spectrum of NODC-800, i.e., D (originating from the disordered carbon [29]) and $\mathrm{G}$ (stemming from the $\mathrm{sp}^{2}$-hybridized graphitic carbon [29]) bands can be clearly observed at around $1340 \mathrm{~cm}^{-1}$ and $1595 \mathrm{~cm}^{-1}$, respectively (Figure 1D illustration). $I_{\mathrm{D}}$ is a little lower than $I_{\mathrm{G}}$, confirming that the relatively high degree of graphitization although the large amount of distortions [30, $31]$.

In order to qualitatively characterize the chemical functional groups of NODC-800, FTIR was collected and shown in Figure 1E. The strong peak at $3434 \mathrm{~cm}^{-1}$ is designated to $\mathrm{O}-\mathrm{H}$ stretching vibration (adsorbed water or hydroxyl groups) [32]. The peak near $1632 \mathrm{~cm}^{-1}$ derives from $\mathrm{C}=\mathrm{O}$ stretching vibration [33]. The peak around $1460 \mathrm{~cm}^{-1}$ should be attributed to $\mathrm{C}=\mathrm{C}$ and/or $\mathrm{C}=\mathrm{N}$ bands [34]. The broad peak centered at $1114 \mathrm{~cm}^{-1}$ is characteristic of $\mathrm{C}-\mathrm{O}$ bonds [35]. These results declare $\mathrm{O}$ and $\mathrm{N}$ elements exist in NODC-800. Nitrogen and oxygen dual-doped carbon materials tend to have high electrical conductivity and good surface wettability [36], which is effective in improving electrochemical performance.

XPS is collected to investigate the elemental content and the chemical composition of the final product. The XPS full spectrum exhibits a dominant C 1s peak (ca. $284 \mathrm{eV}$ ), a weak $\mathrm{N}$ 1s peak (ca. $400 \mathrm{eV}$ ) and a strong $\mathrm{O} 1 \mathrm{~s}(\mathrm{ca.532} \mathrm{eV}$ ), indicating that $\mathrm{N}$ and $\mathrm{O}$ have been doped into the porous carbon material (Figure 1F). The content of $\mathrm{C}, \mathrm{N}$ and $\mathrm{O}$ in NODC-800 material was calculated to be 83.2, 0.4 and 16.4 (at.\%), respectively. Figure $1 \mathrm{G}$ shows that the high-resolution C 1s XPS spectrum of NODC-800 can be fitted into four peaks. The percentage of $\mathrm{sp}^{2} \mathrm{C}$ atoms (ca. $284.3 \mathrm{eV}$ ) is $56 \%$, demonstrating that more than half of the $\mathrm{C}$ atoms are in the form of conjugated honeycomb lattice [37]. The peak at $285.1 \mathrm{eV}$ originating from $\mathrm{sp}^{3} \mathrm{C}$ atoms identifies the amorphous carbon [9], which re-confirms the partially graphitized structure of NODC-800, identical with XRD and Raman results. The broad peak in the range of 286-289 eV indicates $\mathrm{C}-\mathrm{N}$ and/or $\mathrm{C}-\mathrm{O}$ species remaining in the prepared sample 
$[32,37,38]$. The high-resolution XPS spectrum of $\mathrm{O} 1 \mathrm{~s}$ is decomposed into three peaks (Figure 1H), designated to $\mathrm{C}=\mathrm{O}(531.4 \mathrm{eV}), \mathrm{C}-\mathrm{OH}(531.9 \mathrm{eV})$ and $\mathrm{C}-\mathrm{O}-\mathrm{C}(533.15 \mathrm{eV})$, respectively $[39,40]$. The high-resolution XPS spectrum of $\mathrm{N} 1 \mathrm{~s}$ is deconvoluted into four peaks (Figure 1I), attributed to pyridinic N (398.2 eV), pyrrolic N (399.7 eV), graphitic $\mathrm{N}(400.6 \mathrm{eV})$ and oxydic $\mathrm{N}(405.5 \mathrm{eV})$, respectively [28,41]. According to the literatures, these doped oxygen and nitrogen elements avail electrochemical ORR and SCs [42]. Pyridinic N, pyrrolic N and graphitic N are commonly believed to play significant roles in ORR electrocatalytic process [28], although the dominative species are still controversial. Sun. et al has reported that graphitic N may be indispensable for ORR catalytic activity [43]. Graphitic $\mathrm{N}$ atoms are doped into graphene layer and substitute for $\mathrm{C}$ atoms within the graphene plane, which assists electrons transfer from neighboring $\mathrm{C}$ to $\mathrm{N}$ atoms and leads to the decrease of electron density on the $\mathrm{C}$ nuclei, hereby facilitating $\mathrm{O}_{2}$ molecules adsorption on the adjacent $\mathrm{C}$ atoms and weakening O-O chemical bonds [44]. Oxygen-containing groups of NODC-800 can enhance its acidity (electron acceptor properties), while nitrogen-containing groups can enhance its basicity (electron donor properties). Both of them may synergistically act to effectively improve the capacitance through increasing faradaic reactions, i.e. pseudocapacitance effect $[45,46]$.

As discussed above, oxygen and nitrogen dual-doped carbon material with partial graphitization structure was successfully synthesized from poplar catkins. As expected, its electrocatalytic ORR performance was systematically investigated in alkaline electrolyte. The ORR catalytic activity of NODC-800 was first measured by cyclic voltammetry $(\mathrm{CV})$ in $\mathrm{O}_{2}$-saturated $0.1 \mathrm{~mol} \mathrm{l}^{-1} \mathrm{KOH}$ solution (Figure 2A). NODC-800 shows a more positive ORR potential $(-0.060 \mathrm{~V}$ versus $\mathrm{Hg} / \mathrm{HgO})$ and higher current density (0.84 $\mathrm{mA} \mathrm{cm}^{-2}$, Figure $\left.2 \mathrm{~A}(\mathrm{~b})\right)$ than those of commercial Pt/C catalyst $(-0.074$ $\mathrm{V}$ versus $\mathrm{Hg} / \mathrm{HgO}$ and $0.60 \mathrm{~mA} \mathrm{~cm}^{-2}$, Figure 2A (a)), demonstrating a remarkable ORR catalytic activity. The linear scan voltammogram (LSV) curves of NODC-800 at 
different rotating speeds display that the diffusion limiting current desities increase with the rotating speeds from 400 to $2025 \mathrm{rpm}$ (Figure S1A,). The Koulecky-Levich (K-L) plots of NODC-800 at different potentials show good linearity, suggesting that the electron-transfer number of ORR at different electrode potentials are similar (Figure S1B). The inset of Figure S1B exhibits that the electron-transfer number is close to 4 at $-0.75 \mathrm{~V}$, demonstrating that the ORR process on NODC-800 is a approximate four-electron transfer reaction. Compared with commercial $\mathrm{Pt} / \mathrm{C}$ catalyst, the onset potential and diffusion limiting current density of ORR on NODC-800 are close to those on commercial Pt/C catalyst (Figure S1C), showing the outstanding ORR catalytic activity of NODC-800. Compared with other carbon materials reported recently, NODC-800 shows superior ORR performance to most of them, as summarized in Table S1. A cycling durability test was carried out at $50 \mathrm{mV} \mathrm{s}^{-1}$ within a scan range of -0.6 to $0.2 \mathrm{~V}$ versus $\mathrm{Hg} / \mathrm{HgO}$ (Figure 2B), exhibiting a negligible attenuation after 1000 cycles, while Pt/C catalyst displays a 5.4\% decrease of current density under the same condition (Figure S1D).

For practical application, an ideal ORR catalyst ought to resist methanol cross-over effect and $\mathrm{CO}$ poisoning effect. The toleration to methanol cross-over was measured in $\mathrm{O}_{2}$-saturated $0.1 \mathrm{~mol} \mathrm{l}^{-1} \mathrm{KOH}$ solution at $50 \mathrm{mV} \mathrm{s}^{-1}$ (Figure $\left.2 \mathrm{C}, \mathrm{D}\right)$, into which $(\sim 30 \mathrm{ml}$ $\mathrm{KOH}$ solution) $1 \mathrm{ml}$ methanol was introduced, the CV curves of NODC-800 have no noticeable change, indicating its good resistance to methanol cross-over effect, whereas the introduction of methanol made ORR peak completely disapear and a pair of new peaks appear in the case of commercial $\mathrm{Pt} / \mathrm{C}$ catalyst. The resistance to $\mathrm{CO}$ poisoning effect was tested with chronoamperometry in $\mathrm{O}_{2}$-saturated $0.1 \mathrm{~mol}^{-1} \mathrm{KOH}$ solution at $0.3 \mathrm{~V}$ (Figure $2 \mathrm{E}, \mathrm{F}$ ). When $\mathrm{N}_{2}$ or $\mathrm{CO}$ was introduced into the electrolyte at $2500 \mathrm{~s}$, the ORR current for NODC-800 had a similar attenuation, demonstrating NODC-800 was insensitive to $\mathrm{CO}$, while the ORR current for $\mathrm{Pt} / \mathrm{C}$ showed a precipitously decay after the introduction of $\mathrm{CO}$, indicating the $\mathrm{CO}$-poisoning effect on $\mathrm{Pt} / \mathrm{C}$ catalyst, which limits the energy conversion efficiency and retards the ORR 
[47,48]. All these results indicate NODC-800 eliminates the poor resistance to methanol cross-over and $\mathrm{CO}$ poisoning effect and delivers remarkable selectivity for ORR.

Pyrolysis temperature always plays an important role in the ORR performance of carbon catalysts. NODC-600, NODC-700, NODC-800 and NODC-900 are much alike in morphology (Figure S2). Further insight into surface area and pore structure was analyzed by $\mathrm{N}_{2}$ adsorption-desorption isotherm and the results shown in Figure S3A and Table 1. The IV-type isotherms demonstrate the existence of mesopore and micropore. The surface areas of NODC-600, NODC-700 and NODC-900 are higher than $1350 \mathrm{~m}^{2} \mathrm{~g}^{-1}$, and their total pore volumes are larger than $1.1 \mathrm{~cm}^{3} \mathrm{~g}^{-1}$, suggesting that the carbon materials derived from poplar catkins are highly porous. Their XRD patterns are shown in Figure S3B. (002) diffraction of disordered carbon and (101) diffraction of graphitized carbon are observed at $2 \theta \approx 25^{\circ}$ and $43^{\circ}$, indicating their partial graphitization structure. As pyrolysis temperature rises from $600{ }^{\circ} \mathrm{C}$ to $900{ }^{\circ} \mathrm{C}$, $\mathrm{D}$ and $\mathrm{G}$ bands located at around $1340 \mathrm{~cm}^{-1}$ and $1595 \mathrm{~cm}^{-1}$ in their Raman spectra do not shift visibly. FTIR results shown in Figure S3D, certify the presence of $\mathrm{O}$ and $\mathrm{N}$ atoms on the surface of NODC-600, NODC-700 and NODC-900. The further exploration of $\mathrm{N}$ species on their surface was caried out by XPS (Figure S4), and the relative species ratios of $\mathrm{N}$ element vary from one sample to another, summarized in Table 1. In comparison, NODC-800 possesses a higher concentration of graphitic N, which is beneficial to ORR process. This confirms that $800{ }^{\circ} \mathrm{C}$ is the optimum temperature for synthesizing ORR electrocatalyst from poplar catkin in this case, proven by $\mathrm{CV}$ results shown in Figure S5, i.e. NODC-800 delivers a superior ORR electrocatalytic activity to those of NODC-600, NODC-700 and NODC-900. 
Table 1. Pore structure and nitrogen contents of NODC.

\begin{tabular}{cccccccccc}
\hline Sample & $\begin{array}{c}\mathrm{S}_{\mathrm{BET}^{\mathrm{a}}} \\
\mathrm{m}^{2} \mathrm{~g}^{-1}\end{array}$ & $\begin{array}{c}\mathrm{V}_{\mathrm{T}}^{\mathrm{b}} \\
\mathrm{cm}^{3} \mathrm{~g}^{-1}\end{array}$ & $\begin{array}{c}\mathrm{V}_{\text {micro }} \\
\mathrm{cm}^{3} \mathrm{~g}^{-1}\end{array}$ & $\begin{array}{c}\mathrm{d}_{\text {average }} \\
\mathrm{nm}\end{array}$ & $\begin{array}{c}\mathrm{Total}^{\mathrm{e}} \\
\mathrm{N} \\
(\text { At.) }\end{array}$ & $\begin{array}{c}\text { Pyridinic } \\
\mathrm{N} \\
\text { (At.\%) }\end{array}$ & $\begin{array}{c}\text { Pyrrolic } \\
\text { (At.\%) }\end{array}$ & $\begin{array}{c}\text { Graphitic } \\
\text { (At.\%) }\end{array}$ & $\begin{array}{c}\text { Oxydic } \\
\text { (At.\%) }\end{array}$ \\
\hline NODC-600 & 1525.3 & 1.18 & 0.28 & 3.2 & 0.7 & 19 & 49 & 24 & 8 \\
NODC-700 & 1351.4 & 1.26 & 0.13 & 3.8 & 0.51 & 25 & 30 & 35 & 10 \\
NODC-800 & 1462.5 & 1.31 & 0.18 & 3.6 & 0.4 & 10 & 13 & 53 & 24 \\
NODC-900 & 1388.8 & 1.17 & 0.21 & 3.5 & 0.5 & 25 & 35 & 32 & 9 \\
\hline
\end{tabular}

${ }^{\text {a) }}$ BET surface area, ${ }^{\text {b) }}$ total pore volume $\left(\mathrm{P} / \mathrm{P}_{\mathrm{o}}=0.995\right),{ }^{\mathrm{c})}$ t-Plot micropore volume, ${ }^{\mathrm{d}}$ ) BJH adsorption average pore diameter, ${ }^{\text {e) }}$ total nitrogen content of NODC-800.

As literatures report, porous carbon materials with abundant surface functional groups are beneficial for rapid charge transfer and storage [49], and nitrogen/oxygen-doping is conducive to enhance their capacitance behavior $[45,46$, 50]. Therefore, NODC-800 is expected to show a good performance as SCs electrodes. Galvanostatic charge/discharge was firstly measured with three-electrode system in 1 mol $\mathrm{l}^{-1} \mathrm{H}_{2} \mathrm{SO}_{4}$ solution (Figure $3 \mathrm{~A}$ ), and the profiles show good linearity and symmetry, confirming that NODC-800 electrode delivers a highly stable specific capacity [51, 52]. Its specific capacitance calculated from galvanostatic charge/discharge curves is $251 \mathrm{~F}$ $\mathrm{g}^{-1}$ at $0.5 \mathrm{~A} \mathrm{~g}^{-1}$ (area-specific capacitance is $17.1 \mu \mathrm{F} \mathrm{cm}$ ), which is higher than those of many carbon materials derived from biowaste, such as nitrogen-doped carbon derived from silk (242 $\mathrm{F} \mathrm{g}^{-1}$ at $0.1 \mathrm{~A} \mathrm{~g}^{-1}$ ) [17], porous carbons from paper pulp (162.2 $\mathrm{F}$ $\mathrm{g}^{-1}$ at $\left.0.1 \mathrm{~A} \mathrm{~g}^{-1}\right)$ [53], carbon aerogels from chitosan (197 $\mathrm{F} \mathrm{g}^{-1}$ at $\left.0.2 \mathrm{~A} \mathrm{~g}^{-1}\right)$ [54], microporous carbons from microalgae $\left(200 \mathrm{~F} \mathrm{~g}^{-1}\right.$ at $\left.0.1 \mathrm{~A} \mathrm{~g}^{-1}\right)$ [55], and $\mathrm{N}$-doped carbon from soybean $\left(176 \mathrm{~F} \mathrm{~g}^{-1}\right.$ at $\left.0.2 \mathrm{~A} \mathrm{~g} \mathrm{~g}^{-1}\right)$ [56] et al. The detailed comparison is summaried in Table S2. The inset of Figure 3A displays corresponding galvanostatic charge/discharge curves, which is nearly symmetric triangle with a little IR drop. Electrochemical impedance spectroscopy (EIS) can provide dynamic information of both electrode and electrolytes [57]. Figure 3B clearly shows a small semicircle in the high frequency region. The charge transfer resistance is estimated to be $0.88 \Omega$ before 1000 cycles, indicating the higher electrical conductivity of NODC-800 [58, 59]. The $45^{\circ}$ sloped line in small-scale and the vertical line demonstrate the fast ions and 
electrons transfer/diffusion to nanopores and excellent capacitive of the whole system [60]. After 1000 cycles, the EIS spectrum of NODC-800 just slightly changes, and the charge transfer resistance decreases to $0.73 \Omega$, demonstrating its better electrical conductivity and outstanding durability. Cycle life measurement was carried out at current densities of $1 \mathrm{~A} \mathrm{~g}^{-1}$ for 1000 cycles and $20 \mathrm{~A} \mathrm{~g}^{-1}$ for 10,000 cycles to evaluate the stability of NODC-800. Figure 3C shows that the specific capacitance of NODC-800 electrode always retains more than $96 \%$ of the initial specific capacitance, indicating the excellent electrochemical reproducibility and cycle stabiblity of NODC-800 electrode. The Coulombic efficiency of NODC-800 is $98.5 \%$ at $1 \mathrm{~A} \mathrm{~g}^{-1}$ and $99.5 \%$ at $20 \mathrm{~A} \mathrm{~g}^{-1}$, exhibiting that there are nearly no side reactions [56]. Based on the calculation from the galvanostatic charge/discharge test with two-electrode system (the inset of Figure 3D), the highest energy and power density for assembled cell are 19.2 $\mathrm{W} \mathrm{h} \mathrm{Kg}^{-1}$ and $11160.5 \mathrm{~W} \mathrm{Kg}^{-1}$ (Figure 3D), respectively, which exceeds those of many carbons, such as carbons from pomelo peel [61], activated carbons from coconut shell [62], dense 3D graphene macroforms [63], activation of graphene aerogel [64] and so on. The outstanding long-term cycle stability and high energy and power density of NODC-800 electrode are crucial to the cost-effectiveness of the whole energy storage devices. Compared with the carbons from catkins in literatures, NODC-800 behaves as multi-functional carbon material to deliver superior ORR performance (peak potential: $0.824 \mathrm{~V}$ vs RHE; current density: $\left.0.84 \mathrm{~mA} \mathrm{~cm}^{-2}\right)$ to that of CMTs ( $0.627 \mathrm{~V}$ versus RHE, $\sim 0.37 \mathrm{~mA} \mathrm{~cm}^{-2}$ ) [65] and Fe/N/CNT@PCF (0.717 V versus RHE, $\left.0.848 \mathrm{~mA} \mathrm{~cm}^{-2}\right)$ [66] and exhibit higher area-specific capacitance for SCs $\left(17.1 \mu \mathrm{F} \mathrm{cm}{ }^{-2}\right)$ than that of CMF-2 $\left(10.6 \mu \mathrm{F} \mathrm{cm}^{-2}\right)$ [67] and HPNCT-800 (16.4 $\left.\mu \mathrm{F} \mathrm{cm}^{-2}\right)$ [68]. Even though NODC-800 possesses a slightly lower area-specific capacitance than that of N, S-PCNs1-1 [10], the more economical preparation makes it a promising electrode material for practical application. $\mathrm{ZnCl}_{2}$ is a mild and non-corrosive activator, but $\mathrm{KOH}$ has serious corrosion influence on laboratory equipment. The detailed comparison is summaried in Table S3. The narrow pore size distribution of NODC-800 endows it with potential 
application as SCs electrode in organic or ionic liquid electrolyte [69], which is worth attention and onging now.

To make the best use of poplar catkins, OCA was prepared via another method to pyrolyze poplar catkins without any activation, which is applied as absorbent for oil and organic solvent. Poplar catkins have no obvious morphology change after thermal treatment (Figure 4A and B). The photo of OCA floating on sonchus asper easily discovers its light-weight (Figure 4C). FESEM image clearly displays the ample nano-scale holes uniformly distributed on the surface of OCA (Figure 4D), and TEM image also reveals its porous and fluffy structure (Figure 4E). Nitrogen adsorption-desorption isotherm analysis shows that OCA has a surface area up to $2262.93 \mathrm{~m}^{2} \mathrm{~g}^{-1}$ and the average pore diameter is $3.47 \mathrm{~nm}$ (Figure S6A). The porous structure of the carbon aerogel should be beneficial for oil/water separation.

CA measurement is carried out to investigate the surface lipophilicity of OCA. Figure 4F shows $6 \mu \mathrm{l}$ corn oil was immediately absorbed when it was dropped on the flat surface of OCA sheet, showing CA of $4.4^{\circ}$, which indicates that OCA has a superoleophilic surface. The porous structure and the superoleophilic surface make OCA an ideal oil/water separators. As shown in Figure $4 \mathrm{G}$ and Movie S1, it can completely adsorb the used pump oil floating on water within several minutes, realizing oil/water separation, and the absorption capacity is 150 times as much as its own weight. Dichloroethane was also used to investigate the efficiency of OCA in separating organic solvent from water (Figure 6G and Movie S2). OCA exhibited a robust capacity to retrieve all dichloroethane from water, and the absorption capacity is 170 times as much as its own weigh, exhibiting an outstanding ability for the facile clean up of oils and organic solvents from water. Besides, OCA has high absorption capacity for many oils and various organic solvents, including alcohols, hydrocarbons, ketones, ethers, and aromatic compounds, all of which are daily or industry pollutants (Figure $4 \mathrm{H}$ ). The absorption capacity of OCA for these liquids is as high as $81 \sim 171$ times as much as its own weight, which is even higher than or comparable to many 
carbon materials absorbents, such as carbon nanotubes-based sorbents [11, 70, 71], grapheme-based absorbents $[11,72,73]$, carbon aerogel $[10,74,75]$, although it is still lower than some absorbent materials [76-78]. These are detailedly summaried in Table S3. The recycle experiment of OCA was performed using waste pump oil as the model adsorbate. In one cycle, the waste pump oil fully permeated through OCA, and the OCA was then heated at $800{ }^{\circ} \mathrm{C}$ in $\mathrm{N}_{2}$ for 2 hours to regenerate the carbon, and this process was repeated 8 times to measure the reusability of OCA material. The oil mass removed from water has no significant decrease after eight cycles, indicating the outstanding recycle performance of OCA (Figure 4I). Compared with the carbon material absorbent from catkins in literatures, OCA with similar absorption capacity for oil and organic solvents to HCFSs-9 not only dilevers superior recycle performance to HCFSs-9, but also can be obtained at lower pyrolysis temperature [79].

In short, the simple and gentle preparation method and the excellent absorption capacity and recyclability make it possible to achieve practical application. The electrochemical performance of OCA was also investigated, shown in Figure S7. OCA catalyst shows an even more negative ORR potential $(-0.21 \mathrm{~V}$ versus $\mathrm{Hg} / \mathrm{HgO})$ than that of NODC-800 catalyst ( $-0.060 \mathrm{~V}$ versus $\mathrm{Hg} / \mathrm{HgO})$, probably because the $\mathrm{N}$ content of OCA is only 0.09 (at.\%), and graphitic $\mathrm{N}$ content is just $36 \%$, which is indispensable for ORR catalytic process. In addition, NODC-800 exhibits better hydrophilicity $\left(11.1^{\circ}\right)$ than OCA $\left(20.3^{\circ}\right)$, as shown in Figure S6, which facilitates the access of ions to the surface of catalyst, and benefits its ORR performance [8].

\section{Conclusion}

In conclusion, this paper reported multiple methods to utilize poplar catkins in electrochemistry and oil/water separation. NODC-800 with a large number of micropores and mesopores and surface functional groups is prepared from pyrolyzing the mixture of poplar catkins and $\mathrm{ZnCl}_{2}$, delivering an outstanding electrochemical performance for ORR, i.e. NODC-800 not only exhibits superior ORR catalytic 
activity and stability to those of commercial $\mathrm{Pt} / \mathrm{C}$, but also overcomes the limitations of $\mathrm{Pt} / \mathrm{C}$ catalyst such as poor resistance to methanol cross-over and $\mathrm{CO}$ poisoning effect that seriously weaken the performance of FCs. In addition, NODC-800 exhibits a high capacity $\left(\sim 251 \mathrm{~F} \mathrm{~g} \mathrm{~g}^{-1}\right.$ at $\left.0.5 \mathrm{~A} \mathrm{~g}^{-1}\right)$ with nearly $100 \%$ retention rate after 1000 cycles in SCs. OCA, derived from directly carbonizing poplar catkins, shows high absorption capacity and excellent recyclability for oil/water separation. This work is a good example to make the best of raw materials from nature to achieve energy sustainable development, and protect environmental from oils and organic solvents spill.

\section{Acknowledgements}

This work was supported by National Science Foundation of China (21071047 and 21471048), the Research Project of Chinese Ministry of Education (No. 213023A), the Program for New Century Excellent Talents in University of Ministry of Education of China (NCET-11-0944), the Excellent Youth Foundation of Henan Scientific Committee (124100510004), the Program for Innovative Research Team in University of Henan Province (No. 14IRTSTHN005).

\section{References}

[1] J. Deng, M. Li, Y. Wang, Green Chem. 18 (2016) 4824-4854.

[2] C. Zhao, C. Yu, S. Liu, J. Yang, X. Fan, H. Huang, J. Qiu, Adv. Funct. Mater. 25 (2015) 6913-6920.

[3] R. Silva, D. Voiry, M. Chhowalla, T. Asefa, J. Am. Chem. Soc. 135 (2013) 7823-7826.

[4] Z. Pei, H. Li, Y. Huang, Q. Xue, Y. Huang, M. Zhu, Z. Wang, C. Zhi, Energy Environ. Sci. (2017) DOI: 10.1039/C6EE03265F.

[5] R. K. Gupta, M. Dubey, P. Kharel, Z. Gu, Q. H Fan, J. Power Sources 274 (2015) 1300-1305. 
[6] H. Zhu, D. Chen, N. Li, Q. Xu, H. Li, J. He, J. Lu, Adv. Funct. Mater. 25 (2015), 597-605.

[7] S. Gao, J. Su, X. Wei, M. Wang, M. Tian T. Jiang, Z. L. Wang, ACS Nano (2017) DOI: 10.1021/acsnano.6b07183.

[8] S. Gao, Y. Chen, H. Fan, X. Wei, C. Hu, H. Luo, L. Qu, J. Mater. Chem. A 2 (2014) $3317-3324$.

[9] S. Gao, K. Geng, H. Liu, X. Wei, M. Zhang, P. Wang, J. Wang, Energy Environ. Sci. 8 (2015) 221-229.

[10] Y. Li, G. Wang, T. Wei, Z. Fan, P. Yan, Nano Energy 19 (2016) 165-175.

[11] S. Gupta, N.-H. Tai, J. Mater. Chem. A 4 (2016) 1550-1565.

[12] J. Li, D. Li, Y. Yang, J. Li, F. Zha, Z. Lei, Green Chem. 18 (2016) 541-549.

[13] W. Meng, W. Chen, L. Zhao, Y. Huang, M. Zhu, Y. Huang, Y. Fu, F. Geng, J. Yu, X. Chen, C. Zhi, Nano Energy 8 (2014) 133-140.

[14] S. Gao, L. Li, K. Geng, X. Wei, S. Zhang, Nano Energy 16 (2015) 408-418.

[15] L. Chen, T. Ji, L. Brisbin, J. Zhu, ACS Appl. Mater. Interfaces 7 (2015) 12230-12237.

[16] R. Madhu, V. Veeramani, S. M. Chen, A. Manikandan, A. Y. Lo, Y. L. Chueh, ACS Appl. Mater. Interfaces 7 (2015) 15812-15820.

[17] J. Hou, C. Cao, F. Idrees, X. Ma, ACS Nano 9 (2015) 2556-2564.

[18] S. Gao, H. Fan, S. Zhang, J. Mater. Chem. A 2 (2014) 18263-18270.

[19] S. Jiang, Y. Sun, H. Dai, J. Hu, P. Ni, Y. Wang, Z. Li, Electrochim. Acta 174 (2015) 826-836.

[20] Y.-L. Liu, C.-X. Shi, X.-Y. Xu, P.-C. Sun, T.-H. Chen, J. Power Sources 283 (2015) 389-396. 
[21] H. Zhang, X. Liu, G. He, X. Zhang, S. Bao, W. Hu, J. Power Sources 279 (2015) 252-258.

[22] H. X. Zhong, J. Wang, Y. W. Zhang, W. L. Xu, W. Xing, D. Xu, Y. F. Zhang, X. B. Zhang, Angew. Chem. Int. Ed. 53 (2014) 14235-14239.

[23] Q. Liu, C. Chen, F. Pan, J. Zhang, Electrochim. Acta 170 (2015) 234-241.

[24] X. Duan, Z. Ao, H. Sun, S. Indrawirawan, Y. Wang, J. Kang, F. Liang, Z. H. Zhu, S. Wang, ACS Appl. Mater. Interfaces 7 (2015) 4169-4178.

[25] Q. Han, F. Zhao, C. Hu, L. Lv, Z. Zhang, N. Chen, L. Qu, Nano Research 8 (2015) 1718-1728.

[26] X. Bo, Y. Zhang, M. Li, A. Nsabimana, L. Guo, J. Power Sources 288 (2015) 1-8.

[27] H. Yuan, Y. Hou, Z. Wen, X. Guo, J. Chen, Z. He, ACS Appl. Mater. Interfaces 7 (2015) 18672-18678.

[28] G. Tao, L. Zhang, L. Chen, X. Cui, Z. Hua, M. Wang, J. Wang, Y. Chen, J. Shi, Carbon 86 (2015) 108-117.

[29] J. Liang, Y. Jiao, M. Jaroniec, S. Z. Qiao, Angew. Chem. Int. Ed. 51 (2012) 11496-11500.

[30] H. K. Jeong, Y. P. Lee, R. J. Lahaye, M. H. Park, K. H. An, I. J. Kim, C. W. Yang, C. Y. Park, R. S. Ruoff, Y. H. Lee, J. Am. Chem. Soc. 130 (2008) 1362-1366.

[31] J. Hou, C. Cao, F. Idrees, X. Ma, ACS Nano 9 (2015) 2556-2564.

[32] Y. Zhao, W. Ran, J. He, Y. Song, C. Zhang, D. B. Xiong, F. Gao, J. Wu, Y. Xia, ACS Appl. Mater. Interfaces 7 (2015) 1132-1139.

[33] Y. Ji, T. Li, L. Zhu, X. Wang, Q. Lin, Appl. Surf. Sci. 254 (2007) 506-512.

[34] S. Zhang, W. Huang, P. Hu, C. Huang, C. Shang, C. Zhang, R. Yang, G. Cui, J. Mater. Chem. A 3 (2015) 1896-1901. 
[35] A.-N. A. El-Hendawy, Carbon 41 (2003) 713-722.

[36] H. Peng, G. Ma, K. Sun, Z. Zhang, Q. Yang, Z. Lei, Electrochim. Acta 190 (2016) 862-871.

[37] Z. H. Sheng, L. Shao, J. J. Chen, W. J. Bao, F. B. Wang, X. H. Xia, ACS Nano 5 (2011) 4350-4358.

[38] S. Gao, H. Fan, Y. Chen, L. Li, Y. Bando, D. Golberg, Nano Energy 2 (2013) 1261-1270.

[39] X. Wei, Y. Li, S. Gao, J. Mater. Chem. A 5 (2017) 181-188.

[40] J. Y. Cheon, J. H. Kim, J. H. Kim, K. C. Goddeti, J. Y. Park, S. H. Joo, J. Am. Chem. Soc. 136 (2014) 8875-8878.

[41] W. Niu, L. Li, X. Liu, N. Wang, J. Liu, W. Zhou, Z. Tang, S. Chen, J. Am. Chem. Soc. 137 (2015) 5555-5562.

[42] B. You, F. Kang, P. Yin, Q. Zhang, Carbon 103 (2016) 9-15.

[43] D. Geng, Y. Chen, Y. Chen, Y. Li, R. Li, X. Sun, S. Ye, S. Knights, Energy Environ. Sci. 4 (2011) 760-764.

[44] L. Lai, J. R. Potts, D. Zhan, L. Wang, C. K. Poh, C. Tang, H. Gong, Z. Shen, J. Lin, R. S. Ruoff, Energy Environ. Sci. 5 (2012) 7936-7942.

[45] G. Lota, B. Grzyb, H. Machnikowska, J. Machnikowski, E. Frackowiak, Chem. Phys. Lett. 404 (2005) 53-58.

[46] K. Jurewicz, K. Babeł, A. Źiółkowski, H. Wachowska, Electrochim. Acta 48 (2003) 1491-1498.

[47] K. Sasan, A. Kong, Y. Wang, M. Chengyu, Q. Zhai, P. Feng, J. Phys. Chem. C 119 (2015) 13545-13550.

[48] S. Gao, H. Liu, K. Geng, X. Wei, Nano Energy 12 (2015) 785-793. 
[49] L. Zhou, H. Cao, S. Zhu, L. Hou, C. Yuan, Green Chem. 17 (2015) 2373-2382.

[50] G. Lota, K. Lota, E. Frackowiak, Electrochem. Commun. 9 (2007) 1828-1832.

[51] X. Meng, P. E. Savage, D. Deng, Environ. Sci. Technol. 49 (2015) 12543-12550.

[52] C. Long, X. Chen, L. Jiang, L. Zhi, Z. Fan, Nano Energy 12 (2015) 141-151.

[53] H. Wang, Z. Li, J. K. Tak, C. M. B. Holt, X. Tan, Z. Xu, B. S. Amirkhiz, D. Harfield, A. Anyia, T. Stephenson, D. Mitlin, Carbon 57 (2013) 317-328.

[54] P. Hao, Z. Zhao, Y. Leng, J. Tian, Y. Sang, R. I. Boughton, C. P. Wong, H. Liu, B. Yang, Nano Energy 15 (2015) 9-23.

[55] M. Sevilla, W. Gu, C. Falco, M. M. Titirici, A. B. Fuertes, G. Yushin, J. Power Sources 267 (2014) 26-32.

[56] G. A. Ferrero, A. B. Fuertes , M. Sevilla, Sci. Rep. 5 (2015) 1-13.

[57] X. Wei, X. Jiang, J. Wei, S. Gao, Chem. Mater. 28 (2016) 445-458.

[58] H. Kashani, L. Chen, Y. Ito, J. Han, A. Hirata, M. Chen, Nano Energy 19 (2016) $391-400$.

[59] Z. Pei, M. Zhu, Y. Huang, Y. Huang, Q. Xue, H. Geng, C. Zhi, Nano Energy 20 (2016) 254-263.

[60] A. P. P. Alves, R. Koizumi, A. Samanta, L. D. Machado, A. K. Singh, D. S. Galvao, G. G. Silva, C. S. Tiwary, P. M. Ajayan, Nano Energy 31 (2017) 225-232.

[61] Q. Liang, L. Ye, Z.-H. Huang, Q. Xu, Y. Bai, F. Kang, Q.-H. Yang, Nanoscale 6 (2014) 13831-13837.

[62] A. Jain, C. Xu, S. Jayaraman, R. Balasubramanian, J. Y. Lee, M. P. Srinivasan, Micropor. Mesopor. Mater. 218 (2015) 55-61.

[63] J. Qu, Y. Li, S. Lv, F. Gao, C. Geng, M. Wu, J. Phys. Chem. C 119 (2015) 24373-24380. 
[64] X. Sun, P. Cheng, H. Wang, H. Xu, L. Dang, Z. Liu, Z. Lei, Carbon 92 (2015) $1-10$.

[65] Y. Ma, J. Zhao, L. Zhang, Y. Zhao, Q. Fan, X. a. Li, Z. Hu, W. Huang, Carbon 49 (2011) 5292-5297

[66] M. Li, Y. Xiong, X. Liu, C. Han, Y. Zhang, X. Bo, L. Guo, J. Mater. Chem. A 3 (2015) 9658-9667.

[67] F. Ma, J. Wan, G. Wu, H. Zhao, RSC Adv. 5 (2015) 44416-44422.

[68] L. Xie, G. Sun, F. Su, X. Guo, Q. Kong, X. Li, X. Huang, L. Wan, W. Song, K. Li, C. Lv, C.-M. Chen, J. Mater. Chem. A 4 (2016) 1637-1646.

[69] D. Liu, C. Fu, N. Zhang, H. Zhou, Y. Kuang, Electrochim. Acta 213 (2016) 291-297.

[70] B. Ge, Z. Zhang, X. Zhu, G. Ren, X. Men, X. Zhou, Colloids Surf. A 429 (2013) $129-133$.

[71] H. Sun, P. La, Z. Zhu, W. Liang, B. Yang, X. Zhao, C. Pei, A. Li, J. Mater. Sci. 49 (2014) 6855-6861.

[72] J. Wang, Z. Shi, J. Fan, Y. Ge, J. Yin, G. Hu, J. Mater. Chem. 22 (2012) 22459-22466.

[73] H. Bi, X. Xie, K. Yin, Y. Zhou, S. Wan, L. He, F. Xu, F. Banhart, L. Sun, R. S. Ruoff, Adv. Funct. Mater. 22 (2012) 4421-4425.

[74] Y.-Q. Li, Y. A. Samad, K. Polychronopoulou, S. M. Alhassan, K. Liao, ACS Sustain. Chem. Eng. 2 (2014) 1492-1497.

[75] B. Wang, R. Karthikeyan, X.-Y. Lu, J. Xuan, M. K. H. Leung, Ind. Eng. Chem. Res. 52 (2013) 18251-18261.

[76] X. Gui, J. Wei, K. Wang, A. Cao, H. Zhu, Y. Jia, Q. Shu, D. Wu, Adv. Mater. 22 
(2010) 617-621.

[77] Y. Zhao, C. G. Hu, Y. Hu, H. H. Cheng, G. Q. Shi, L. T. Qu, Angew. Chem. Int. Ed. 51 (2012) 11371-11375.

[78] S. Huang, J. Shi, Ind. Eng. Chem. Res. 53 (2014) 4888-4893.

[79] L. Zang, Z. Bu, L. Sun, Y. Zhang, RSC Adv. 6 (2016) 48715-48719. 
Scheme 1. The skematic synthesis of NODC-800 (I) and OCA (II), and their applications.

Figure 1. (A) FESEM image, (B) TEM and FR-TEM images (the inset), (C) nitrogen adsorption-desorption isotherm and pore size distributions (the inset), (D) XRD pattern and Raman spectrum (the inset), (E) FTIR spectrum of NODC-800, (F) full-scan XPS spectrum of NODC-800, high-resolution XPS spectra of C 1s (G), O 1s (H) and N 1s (I) of NODC-800.

Figure 2. (A) CV curves of Pt/C (a) and NODC-800 (b) at a scan rate of $10 \mathrm{mV} \mathrm{s}^{-1}$. (B) electrochemical stability of NODC-800. The resistance to the methanol cross-over effect of NODC-800 (C) and Pt/C (D) tested at a scan rate of $50 \mathrm{mV} \mathrm{s}^{-1}$. The resistance to $\mathrm{CO}$ poisoning effect of NODC-800 (E) and Pt/C (F) tested at $0.3 \mathrm{~V}$ (the percentage of current density (j) vs. time).

Figure 3. (A) specific capacitance and galvanostatic charge/discharge curves (inset) of NODC-800 at different current density, (B) EIS of NODC-800 before and after 1000 cycles, (C) cycle life of NODC-800 at $1 \mathrm{~A} \mathrm{~g}^{-1}$ and $20 \mathrm{~A} \mathrm{~g}^{-1}$ (inset), (D) power density and energy density, corresponding galvanostatic charge/discharge curves (inset) of NODC-800.

Figure 4. (A, B) the photos of poplar catkin before and after carbonization, (C) digital image of OCA standing on sonchus asper, (D) FESEM and (E) TEM images of OCA, (F) CA of OCA with oil, (G) screenshots of the video showing oil/dichloroethane (dyed with Sudan red) in water absorbed by OCA, $(\mathrm{H})$ the absorption capacity of OCA for different oils and organic solvents, and (I) recyclability of OCA for used pump oil $(\mathrm{M}=\mathrm{Mb}-\mathrm{Ma}, \mathrm{Mb}$ and $\mathrm{Ma}$ are the mass of OCA after and before adsorbing used pump oil). 
Scheme 1.

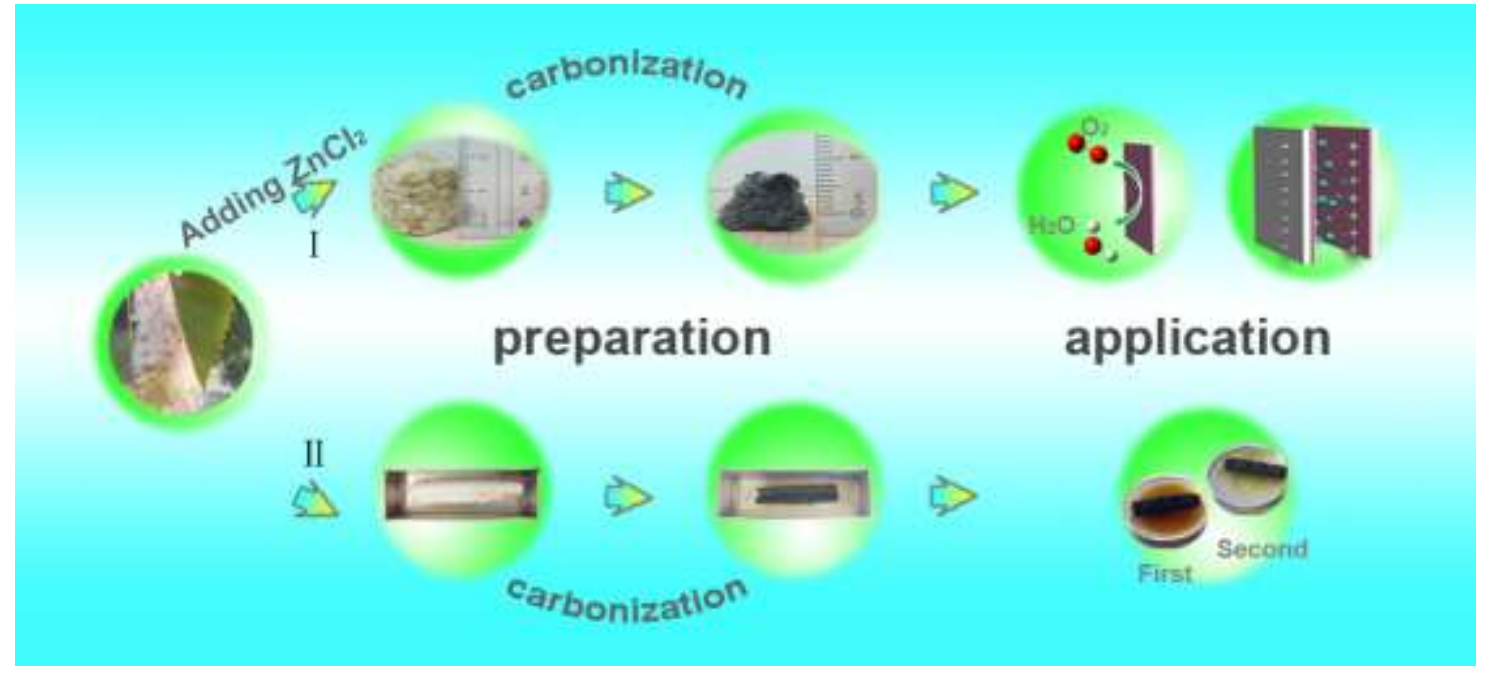


Figure 1.
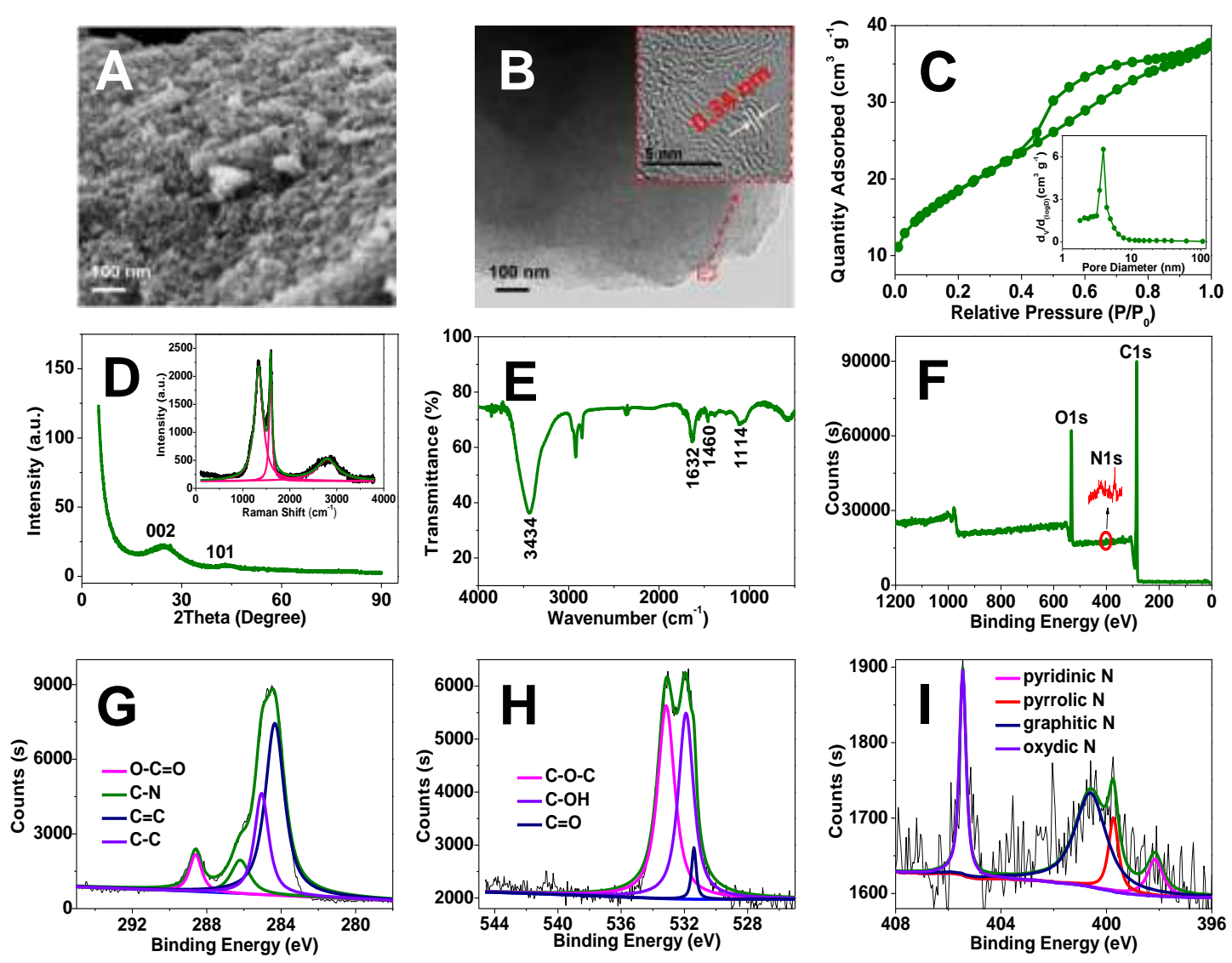
Figure 2.
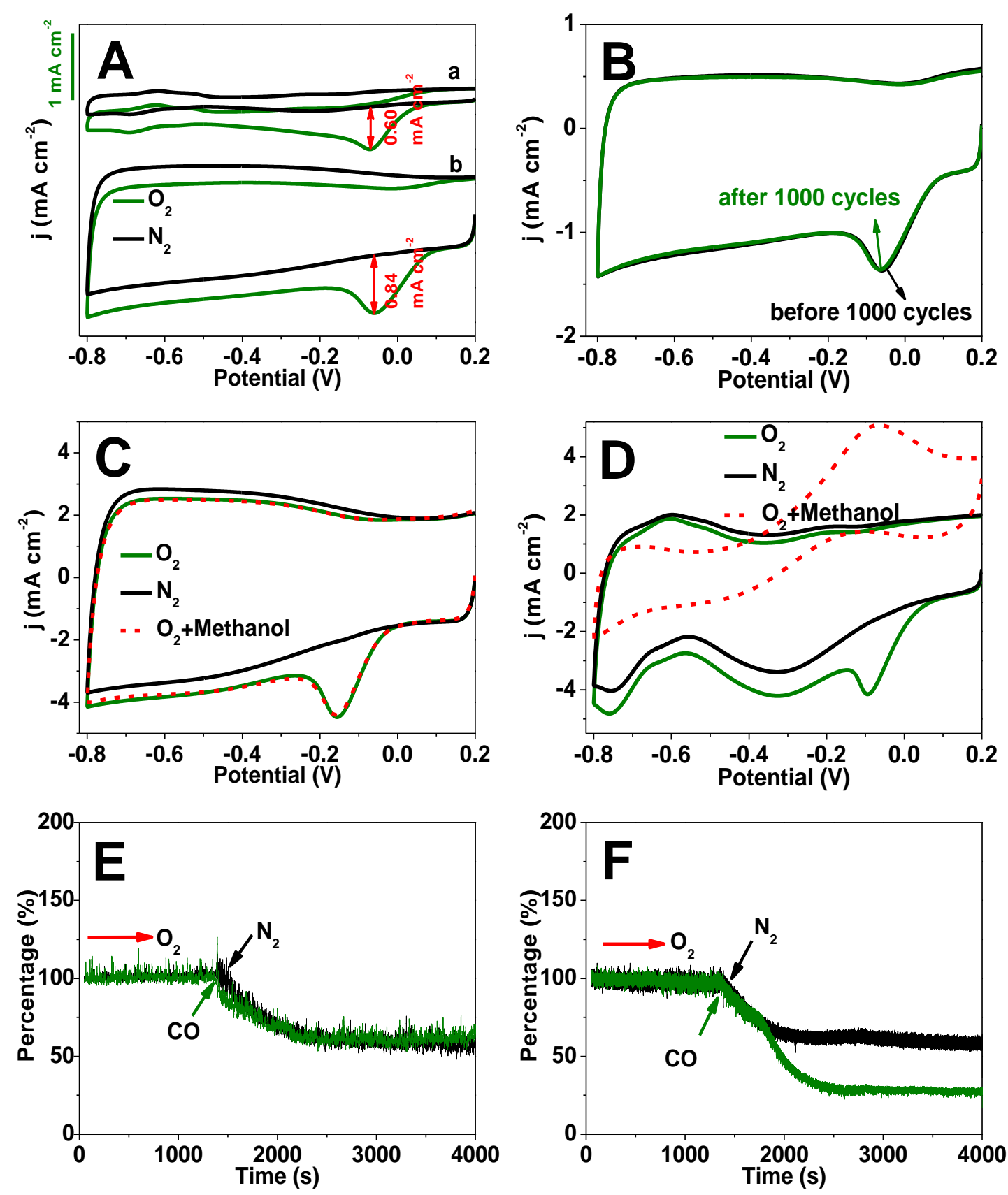
Figure 3.
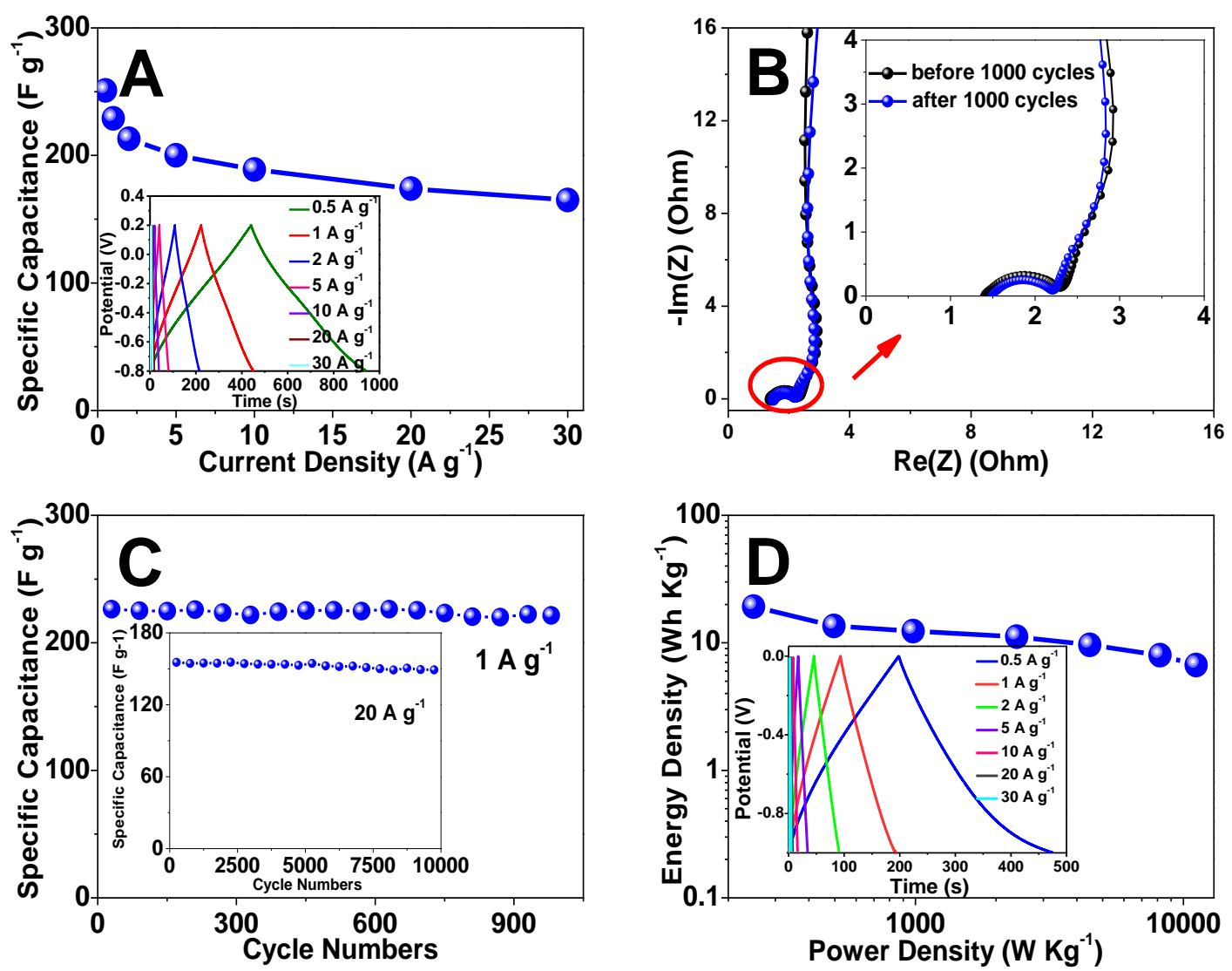
Figure 4.
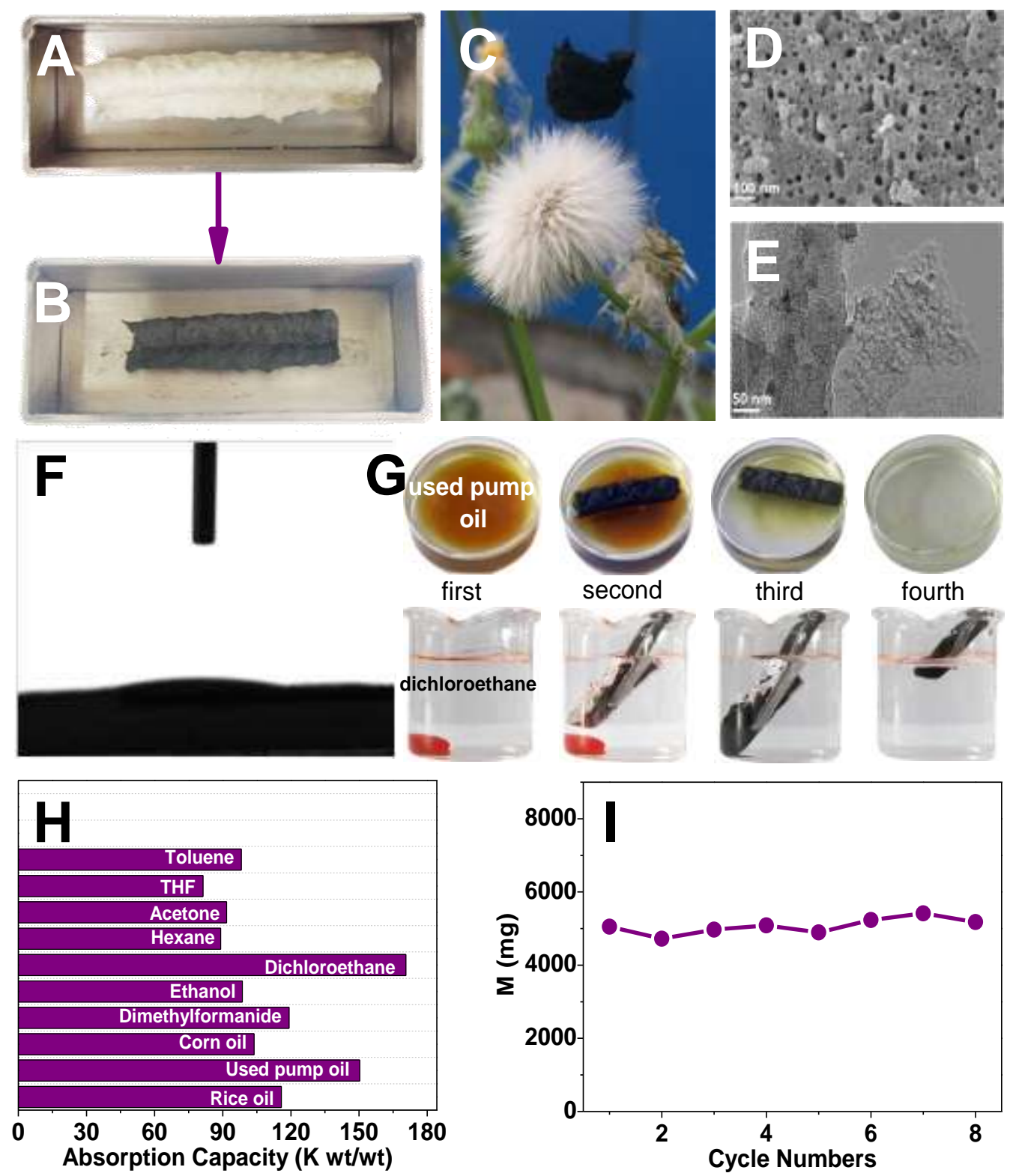

oil
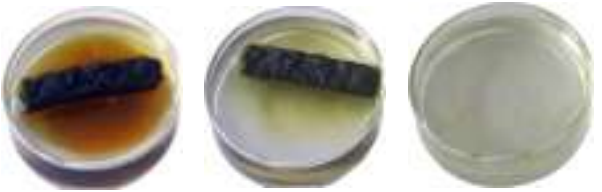

first

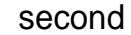

third

fourth
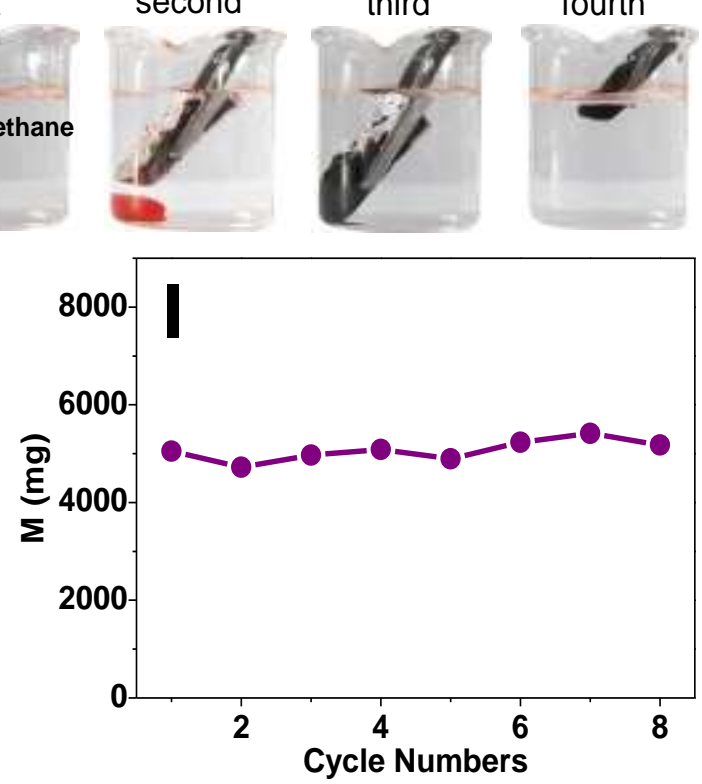


\section{Recent personal portrait photo and a biosketch of each author}

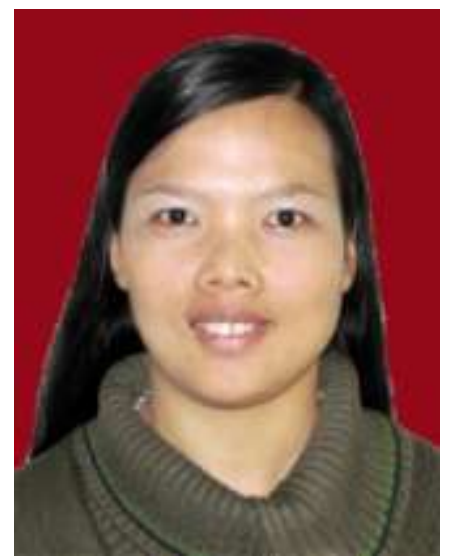

Shuyan Gao received her Ph.D. from the Changchun Institute of Applied Chemistry, Chinese Academy of Sciences, and won YongLing Liu Special Award in 2006. From 2007 to 2009, she worked as a JSPS research fellow at the National Institute of Advanced Industrial Science and Technology. Afterwards, she was a postdoctoral researcher at Hokkaido University. Now, she is a distinguished professor at Henan Normal University. Her research includes green synthesis of carbon-based materials and their composites with controllable dimensions and the applications in energy conversion and storage, sensors, and optoelectronics.

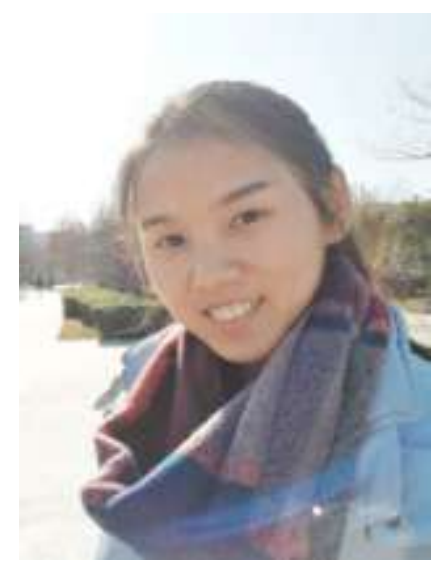

Xiaoge Li is a postgraduate student in Prof. Shuyan Gao's research group at Henan Normal University. Her current research interest is the development of nitrogen-doped carbon for fuel cell and battery application. 


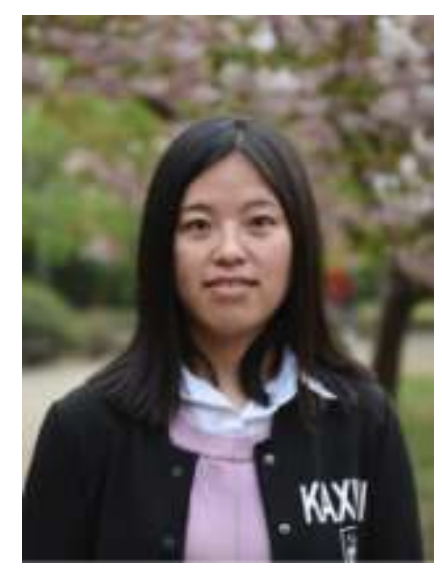

Lingyu Li received her M.S. from Henan Normal University in 2016. Her research interest is the development of metal-free nitrogen-doped carbon for fuel cell and battery application.

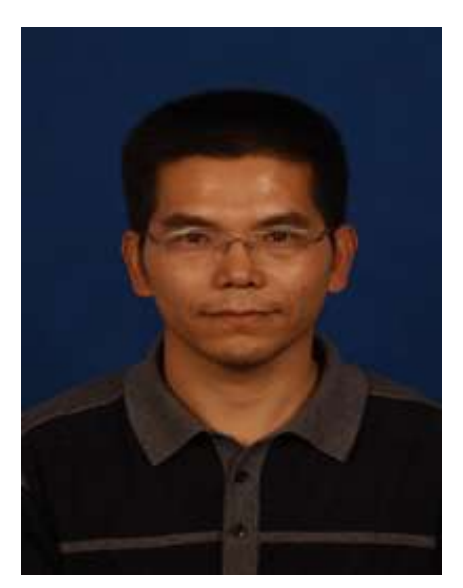

Xianjun Wei received his PhD from Wuhan University, China. He is a full professor in School of Chemistry and Chemical Engineering at Henan Normal University in Xinxiang, China. His research interests are devoted to storage/conversion of energy in electrochemical capacitors, batteries, fuel cells and electrochemical science. 